\title{
(19)
}

\section{EL PLAN DE ACCIÓN PARA LA INTERNACIONALIZACIÓN DE LA ECONOMÍA ESPAÑOLA 2019-2020}

El Consejo de Ministros aprobó, por el Acuerdo de 29 de marzo de 2019, el Plan de Acción para la Internacionalización de la Economía Española 2019-2020, segundo plan bienal que desarrolla la Estrategia de Internacionalización de la Economía Española 2017-2027. El plan ha sido elaborado por el Ministerio de Industria, Comercio y Turismo a través de la Secretaría de Estado de Comercio, con la participación de todos los ministerios con actividad en materia de internacionalización, consultados las comunidades autónomas y el sector privado. Su objetivo principal es impulsar la internacionalización de la economía española, afianzando el dinamismo del sector exterior y su impacto positivo sobre el crecimiento económico y el empleo, a través de la mejora en la competitividad y de la mayor presencia de nuestras empresas en el exterior.

Palabras clave: sector exterior, internacionalización, política comercial.

Clasificación JEL: F13, F14, F20.

\section{Introducción}

El Consejo de Ministros aprobó, el 29 de marzo de 2019, el Plan de Acción para la Internacionalización de la Economía Española 2019-2020, el segundo plan de carácter bienal que se enmarca en la Estrategia de Internacionalización de la Economía Española 20172027. Conforme a lo establecido por la Ley 14/2013, de 27 de septiembre, de apoyo a los

\footnotetext{
* Secretaría de Estado de Comercio. Este artículo ha sido elaborado por Carmen Laín Valenzuela, Subdirectora General de Estrategia de Internacionalización, y por Antonio Bonet Gutiérrez, Jefe de Servicio de la Subdirección General de Estrategia de Internacionalización.

Versión de abril de 2019.

DOI: https://doi.org/10.32796/bice.2019.3111.6827
}

emprendedores y su internacionalización, este plan ha sido elaborado por el Ministerio de Industria, Comercio y Turismo a través de la Secretaría de Estado de Comercio, con la participación de todos los ministerios con actividad en materia de internacionalización, consultados las comunidades autónomas y el sector privado.

La economía española se encuentra en una etapa positiva en lo que se refiere a la internacionalización, si bien no exenta de retos y de amenazas. Desde 2014, el crecimiento económico de nuestro país ha venido acompañado de un superávit por cuenta corriente, un periodo de cinco años consecutivos que no sucedía desde hace más de veinticinco años. 
Con el fin de asegurar que la contribución positiva del sector exterior al crecimiento económico sea de carácter estructural y revierta en la creación de valor y empleo de calidad, es necesario contar con una estrategia a medio y largo plazo que permita la adecuada articulación de los mecanismos que impulsan la internacionalización de la economía española. Se busca así consolidar el cambio en nuestro patrón de crecimiento, con el sector exterior como pilar, propiciando que las empresas españolas, muchas de las cuales iniciaron su proceso de internacionalización empujadas por la debilidad de la demanda interna en la recesión, mantengan su vocación exportadora a pesar de la recuperación de la demanda interna. En este sentido, el Consejo de Ministros aprobó la Estrategia de Internacionalización de la Economía Española 2017-2027 en septiembre de 2017, junto con el primer plan de acción bienal (2017-2018) que la desarrolla y, recientemente, el segundo Plan de Acción 20192020, que es objeto de este artículo.

Se trata de un plan integrador, basado en los principios de coherencia y coordinación en la actuación del Estado y de complementariedad con el sector privado, en el que han participado los organismos de apoyo a la internacionalización, tanto comerciales como financieros -ICEX España Exportación e Inversiones, CESCE, COFIDES e ICO-, así como los distintos ministerios que contribuyen con sus políticas a la internacionalización, coordinados por el Ministerio de Industria, Comercio y Turismo. Además, se han tenido muy en cuenta las orientaciones proporcionadas por el sector privado y han sido consultadas las comunidades autónomas. Este plan es, por tanto, resultado de un esfuerzo notable de coordinación entre todos los actores implicados en la internacionalización.

Frente al resurgimiento de una ola de medidas proteccionistas por parte de algunos países y de otros factores de riesgo no desdeñables, como el brexit o la evolución de los precios del petróleo, España apuesta por continuar con la progresiva liberalización del comercio. La internacionalización de nuestras empresas requiere de un firme apoyo por parte de la Administración para que sigan aprovechando cada vez más las oportunidades que ofrecen los mercados exteriores.

El Plan de Acción 2019-2020 parte de un análisis de la situación actual de la economía española en materia de internacionalización, en el que se identifican una serie de fortalezas: el aumento de la propensión a exportar bienes y servicios, el crecimiento de las exportaciones a mercados no comunitarios, el aumento de exportaciones de contenido tecnológico medio y medio-alto, entre otras; y debilidades: el reducido tamaño medio de los exportadores, la escasa propensión a exportar de la pyme, el bajo grado de digitalización de las empresas, entre otras. A partir de esas fortalezas y debilidades se definen los objetivos y las medidas para el fomento de la internacionalización que se enmarcan en los seis ejes definidos en la estrategia (Esquema 1).

Las medidas se adaptan al nuevo contexto económico nacional e internacional, a los nuevos retos tecnológicos, a los factores de riesgo geopolítico a los que se enfrenta la economía española y buscan cubrir los fallos de mercado (asimetría en la información de las empresas, falta de financiación para determinadas empresas o mercados, externalidades positivas o negativas, entre otros).

Las medidas, que se resumen en el cuarto epígrafe, se basan en las siguientes líneas directrices sobre la política de internacionalización, definidas por el Ministerio de Industria, Comercio y Turismo a través de la Secretaría de Estado de Comercio: 


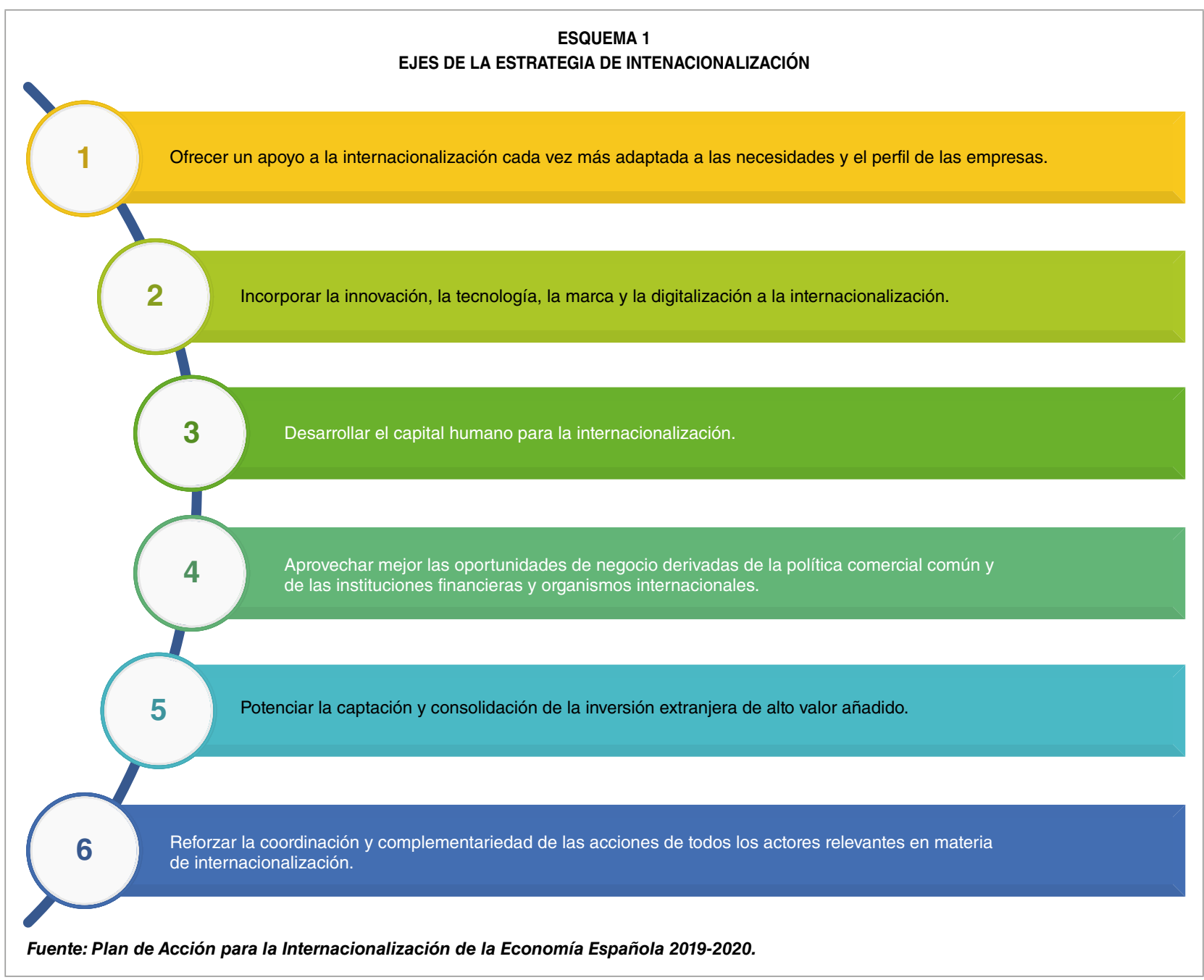

1. Promover una política comercial progresista e inclusiva. Para ello, se instará a que las negociaciones comerciales en el seno de la UE tengan en cuenta capítulos ambiciosos en materia de desarrollo sostenible, comercio, género y pymes, de acuerdo con los Objetivos de Desarrollo Sostenible de la Agenda 2030 y el Acuerdo de París de lucha contra el cambio climático. Además, siguiendo la Estrategia de la Comisión Europea de trade for all ${ }^{1}$, se continuará trabajando para lograr que los beneficios de la

1 http://trade.ec.europa.eu/doclib/docs/2015/october/ tradoc_153846.pdf política comercial comunitaria lleguen a toda la sociedad y a todos los agentes económicos (empresas, trabajadores, etcétera).

2. La Secretaría de Estado de Comercio y sus organismos dependientes incorporarán la sostenibilidad en sus tres dimensiones: internamente, en sus políticas y en sus programas, y como política transversal de todos los actores de la Administración relevantes en materia de internacionalización.

3. Continuar favoreciendo la diversificación de los mercados y sectores de destino de las exportaciones de bienes y servicios españolas, particularmente a través $D$ 
de los planes PASE$^{2}$ (Países con Actuación Sectorial Estratégica): conforme a los resultados que se derivan del análisis cuantitativo y cualitativo de áreas geográficas y de sectores de oportunidad para las empresas españolas en dichas áreas, se identifican actuaciones concretas que permitan adecuar el desempeño exportador español a su potencial.

4. ICEX España Exportación e Inversiones afianzará la cultura orientada al cliente prestando servicios de promoción e información integrales, personalizados y de alto valor añadido. Asimismo, ICEX busca potenciar la atracción de inversiones extranjeras en España, la formación de capital humano y la captación de talento para la internacionalización.

2 La Estrategia PASE se realiza de forma paralela a este plan. En una primera fase los países seleccionados son: Brasil, Canadá, China, Corea, Estados Unidos, India, Japón, Marruecos, México, Rusia, Sudáfrica y Turquía. Para cada uno se han identificado sectores estratégicos, así como actuaciones para el bienio 2019-2020. http://www.comercio.gob.es/ es-ES/comercio-exterior/instrumentos-apoyo/Paginas/Pa\%C3\%ADsescon-Actuaci\%C3\%B3n-Sectorial-Estrat\%C3\%A9gica.aspx
5. Modernizar los instrumentos de apoyo financiero oficial a las empresas para su internacionalización, con el objetivo de contar con instrumentos más ágiles y con mayor alcance en su ámbito de aplicación, y que todo ello redunde en mayor y mejor uso por parte de las empresas españolas.

6. Incrementar el valor añadido de nuestras exportaciones a través de la incorporación de la innovación, la tecnología, la diferenciación de marca y la digitalización en los procesos de internacionalización, así como a través del desarrollo del capital humano.

Por último, la estrategia incorpora un ejercicio de evaluación que permitirá medir los resultados, realizar un seguimiento pormenorizado del cumplimiento de las metas fijadas y valorar el grado de eficacia y de eficiencia de los planes de acción. La evaluación del Plan de Acción 2017-2018 está prevista para el segundo semestre de 2019 y la evaluación de este plan, en 2021.

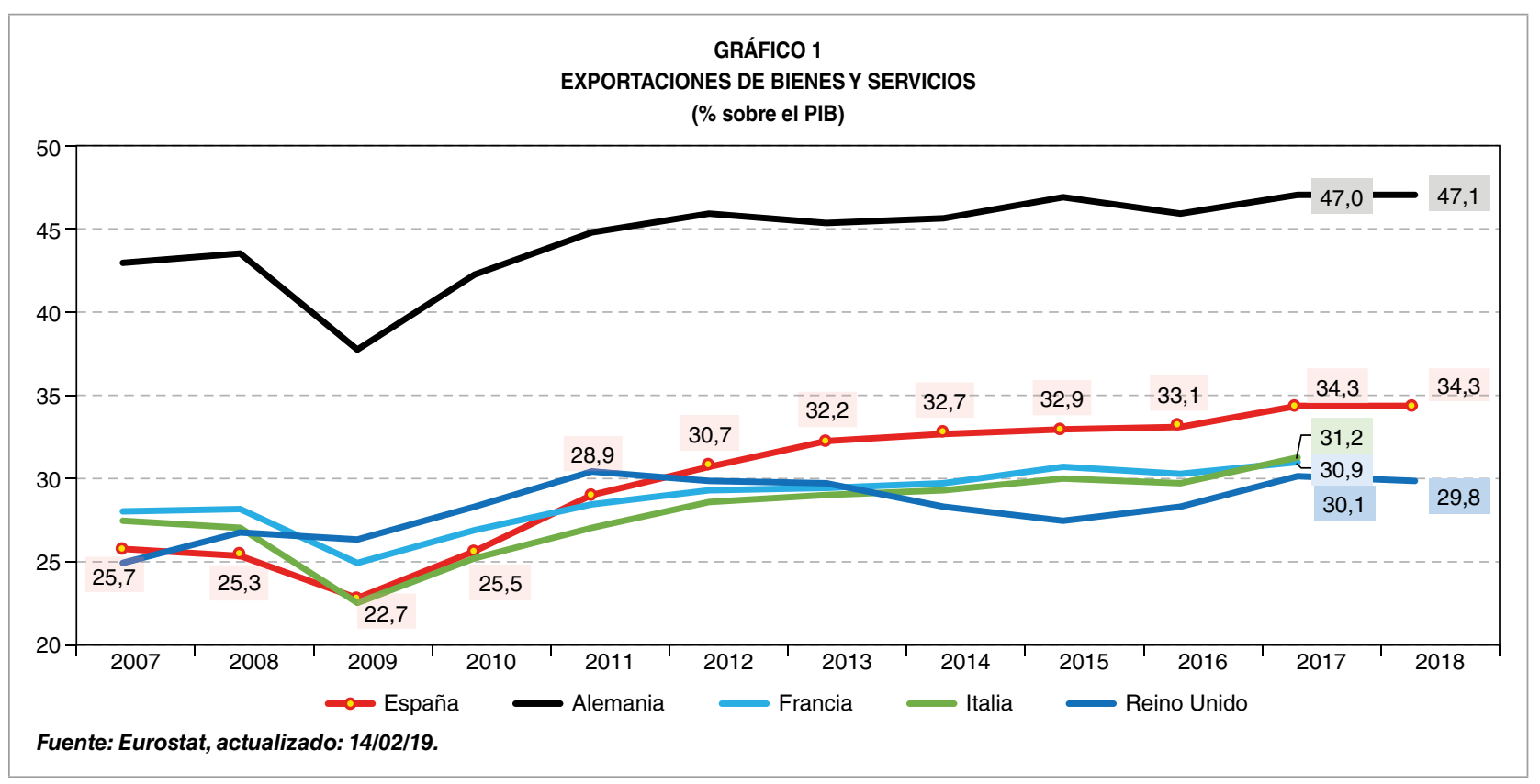




\section{Situación del sector exterior español}

\subsection{Comercio exterior}

El diagnóstico sobre el sector exterior pone de manifiesto que España se encuentra inmersa en un cambio estructural en lo que a su sector exterior se refiere. El buen comportamiento del sector exterior en la última década no solo ha contribuido positivamente al crecimiento, sino que ha consolidado una economía:

1. Más abierta. En un contexto difícil, se ha logrado una creciente apertura de la economía española. Las exportaciones de bienes y servicios se han situado en el 34,3\% del PIB en 2018 (8,6 puntos por encima de su nivel en 2007), un peso superior al de países como Francia, Italia y Reino Unido.

2. Con un mayor número de empresas internacionalizadas. Entre 2013 y 2018 se ha incrementado la base exportadora en más de 10.000 empresas que exportan regularmente, hasta alcanzar un total superior a las 50.000 empresas.

3. Más competitiva y diversificada internacionalmente. España no solo ha conseguido en este periodo romper con su tendencia histórica, al mantener simultáneamente un crecimiento económico dinámico y un saldo superavitario por cuenta corriente y de capitales, sino que se han abierto nuevos mercados. Así, actualmente más de un tercio de las exportaciones se dirigen a países extracomunitarios $(34,3 \%$ de las mercancías y $36,4 \%$ de los servicios en 2017 , frente al $29,1 \%$ y $16,8 \%$ respectivamente en 2007).

España cerró el año 2018 con saldo exterior positivo, lo que supone seis años consecutivos de superávit corriente (desde 2013) y siete años de capacidad de financiación al exterior (desde 2012). Esta buena evolución del saldo de la cuenta corriente ha permitido corregir en 11 puntos el desequilibrio exterior (España tenía el segundo déficit corriente $D$

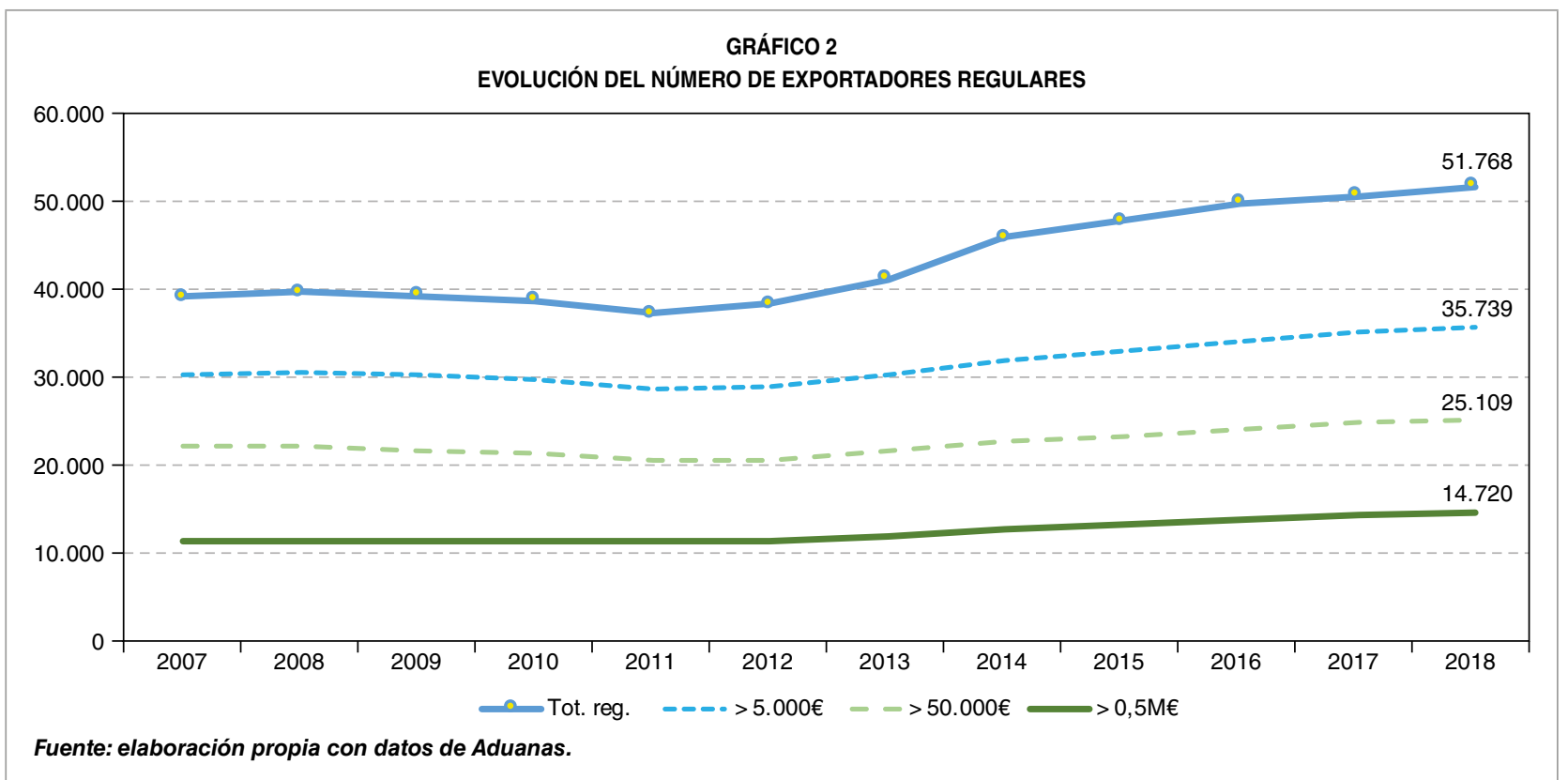




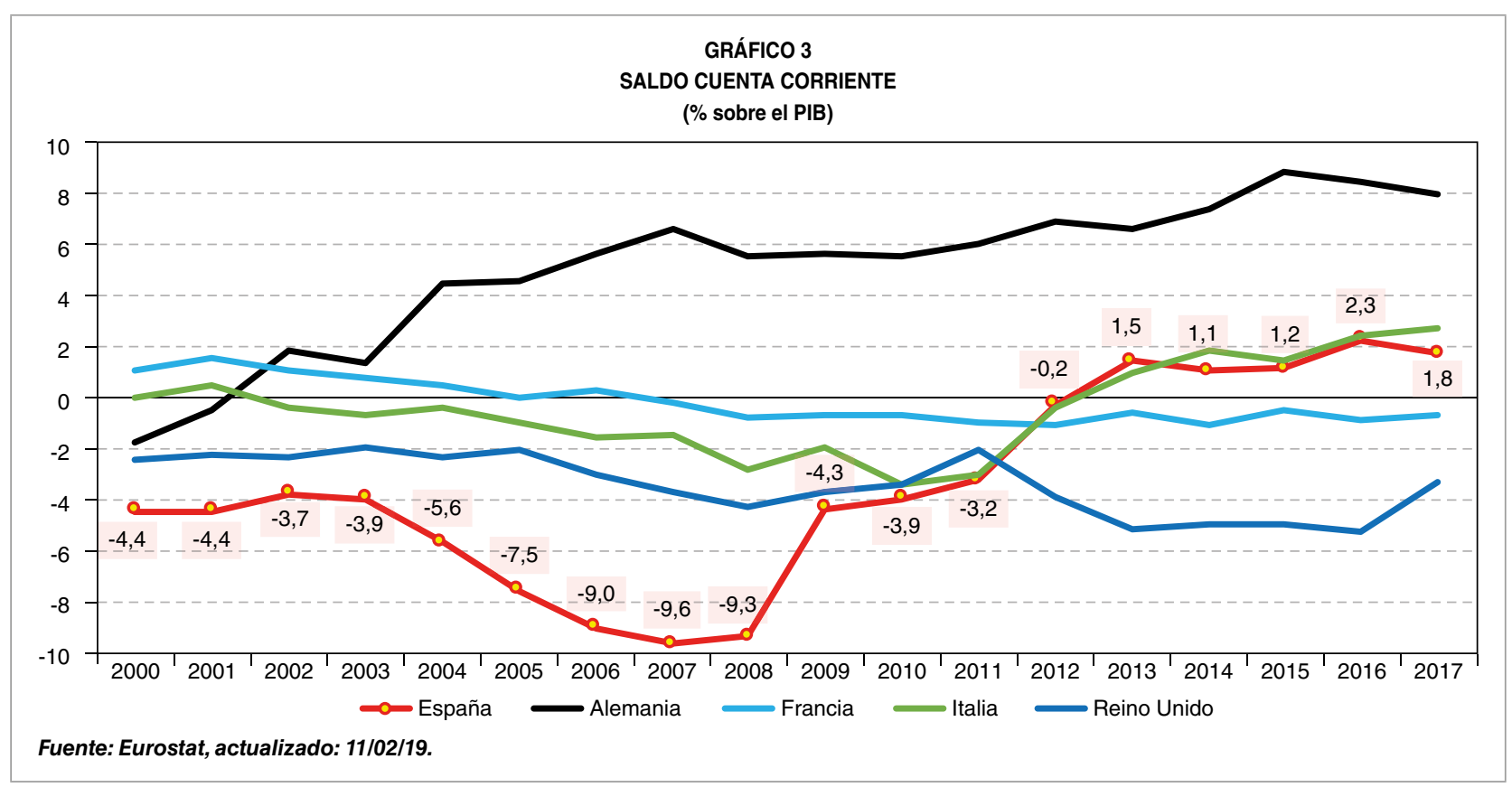

más alto del mundo en el año 2007 en valores absolutos, casi un $10 \%$ en términos de PIB).

Estas tendencias se mantuvieron en 2018, aunque la demanda externa no haya contribuido positivamente al crecimiento del PIB este año, en el que el crecimiento de las importaciones, impulsado por el crecimiento económico nacional, ha superado al de las exportaciones. Con todo, se da continuidad a un novedoso periodo para la economía española con simultaneidad de vigoroso crecimiento y saldo superavitario por cuenta corriente y de capitales, y se siguen observando los aspectos más estructurales de cambio en el patrón exportador español mencionados anteriormente.

\subsection{Inversiones exteriores}

Con respecto a la inversión en los últimos años, la inversión española en el exterior evolucionó positivamente hasta 2017 , año en que inicia el descenso que se agudiza en 2018. En cuanto al comportamiento de la inversión extranjera en España, ha sido de progreso de forma continua hasta llegar a 47.000 millones de euros de IDE bruta en 2018, consolidándose así nuestro país como destino atractivo para la inversión extranjera.

\subsubsection{Inversión española en el exterior}

España se constituye en un inversor mundial de referencia. La implantación de las empresas españolas en el exterior a través de inversión supone una forma avanzada de internacionalización, contribuye a consolidar nuestra presencia en mercados exteriores, a la construcción de cadenas globales de valor que mejora la eficiencia de las empresas y es un importante elemento tractor de exportaciones.

En términos de flujos, entre 2014 y 2018, la inversión española en el exterior ascendió a 162.758 millones de euros de inversión bruta acumulada, 71.364 millones de euros en $\triangleright$ 
valores netos, siendo la desinversión de 91.395 millones ${ }^{3}$.

En 2018 se produjo una caída del $41,02 \%$ de la inversión bruta respecto al año anterior, hasta los 22.416 millones de euros. Por otro lado, la inversión neta aumentó más de un $159 \%$ en 2018, después del descenso del $81,15 \%$ en 2017.

En términos de stock, la posición inversora total española en el exterior en 2016, incluyendo las ETVE, ha tenido un comportamiento positivo, alcanzando 500.033 millones de euros.

La distribución de la posición de inversión española en el exterior desde un punto de vista de áreas geográficas, excluidas ETVE, muestra un predominio de las economías desarrolladas, y, por grandes áreas geopolíticas, de la UE y Latinoamérica. Así, los países OCDE representan el $79,1 \%$; la UE-28, el $43,5 \%$; y Latinoamérica, el $26,3 \%$. Por países, EE UU es el primer país de destino, seguido de Reino Unido, Brasil, México y Hungría.

\subsubsection{Inversión extranjera en España}

La atracción de inversiones extranjeras tiene gran interés, ya que no solo permite incrementar el stock de inversión en el país, sino que además tiene efectos muy positivos en la generación y mantenimiento de puestos de trabajo y en la actividad de las empresas, así como en el desarrollo económico a través de la difusión del conocimiento y la tecnología, el fomento de la competencia, el mayor desarrollo del capital humano nacional y, en definitiva, el impulso de la competitividad.

En términos de flujos, la inversión extranjera bruta en España — descontadas las cifras de

3 Registro de Inversiones de la Secretaría de Estado de Comercio. Los datos de inversión descuentan las cifras de inversión en entidades de tenencia de valores extranjeros (ETVE), salvo indicación en contra. inversión en entidades de tenencia de valores extranjeros (ETVE) - ha crecido durante todo el quinquenio 2014-2018, siendo destacables los aumentos de 2013 a 2015 y especialmente el aumento de 2018 , del $71,24 \%$, que lleva a alcanzar el récord de inversión extranjera en España hasta casi situarse en $\mathbf{4 7 . 0 0 0}$ millones de euros. Por su parte, la inversión extranjera neta se ha incrementado todos los años a excepción de 2017, alcanzando de nuevo un crecimiento récord de más del $153 \%$ en 2018.

En términos de stock, la posición extranjera en España total en 2016, incluidas las ETVE, alcanzó los 425.086 millones de euros de inversión total, un $8,9 \%$ de incremento respecto a 2015.

Como en el caso de la inversión directa española en el exterior, la posición inversora extranjera en España en 2016, excluidas las ETVE y por país beneficiario último, está dominada por las economías desarrolladas. Así, la OCDE representa el $90,2 \%$ del total. Por grandes áreas geográficas, destaca la UE 28 con el $60,1 \%$ (los países de la zona del euro suponen el $45,7 \%)$, seguida por EE UU y Canadá con un $17,1 \%$, Latinoamérica con el $10,4 \%$ y por último Asia y Oceanía con el 7,6\%. Los países con una posición inversora mayor, según criterio de beneficiario último, son: EE UU, Reino Unido, Francia, Italia y México.

\subsection{Retos del sector exterior español}

Se confirma, por tanto, una robusta internacionalización de la economía española, si bien todavía adolece de ciertas debilidades y presenta una serie de retos, entre los que destacan:

1. Incrementar y consolidar la base de empresas que exportan regularmente. 
2. Conseguir que las empresas puedan contar con mercados cada vez más abiertos.

3. Facilitar un mayor acceso de las pymes a los mercados exteriores.

4. Avanzar en la diversificación de los mercados de destino de la exportación y de la inversión, buscando promover la implantación de nuestras empresas en sectores estratégicos en determinados mercados.

5. Mejorar la competitividad de la exportación española a través de un incremento de su valor añadido, siendo necesario para ello incidir en el desarrollo tecnológico, en la innovación y en la transformación digital.

6. Mejorar la inserción de nuestras exportaciones en las cadenas globales de valor.

7. Atraer talento y mejorar la sensibilización y la formación del capital humano de las empresas en materia de acceso a los mercados exteriores.

8. Potenciar la capacidad de España para atraer mayor inversión extranjera.

\section{Objetivos del Plan de Acción 2019-2020}

\subsection{Objetivo general}

La Estrategia de Internacionalización de la Economía Española 2017-2027 y sus planes de acción bienales constituyen la pieza fundamental para alcanzar los retos señalados, siendo su objetivo general el impulso de la internacionalización de la economía española, afianzando así el dinamismo del sector exterior y su impacto positivo sobre el crecimiento económico y el empleo, con carácter estructural, a través de la mejora en la competitividad y de la mayor presencia de nuestras empresas en el exterior.

\subsection{Objetivos específicos}

Considerando el análisis de las fortalezas y debilidades sobre el sector exterior español, el objetivo general se plasma en los siguientes objetivos específicos:

1. Aumentar la propensión a la internacionalización de la economía española y de la base de empresas que exportan regularmente. Particularmente con el foco en mejorar el acceso de las pymes a los mercados exteriores.

2. Diversificar los mercados de destino de exportación e inversión, buscando promover la implantación de nuestras empresas en sectores estratégicos en determinados mercados.

3. Incrementar el valor añadido de las exportaciones y la inserción de nuestras exportaciones en las cadenas globales de valor.

4. Aumentar la atracción de inversión extranjera.

Dichos objetivos llevan asociados unos indicadores de situación del sector exterior que permiten cuantificar su grado de consecución.

\subsection{Objetivos intermedios}

Para incidir sobre estos objetivos específicos, se define una serie de objetivos intermedios. En algunos casos, las políticas necesarias para incidir en algunos de estos objetivos escapan del ámbito de la internacionalización. $\triangleright$ 


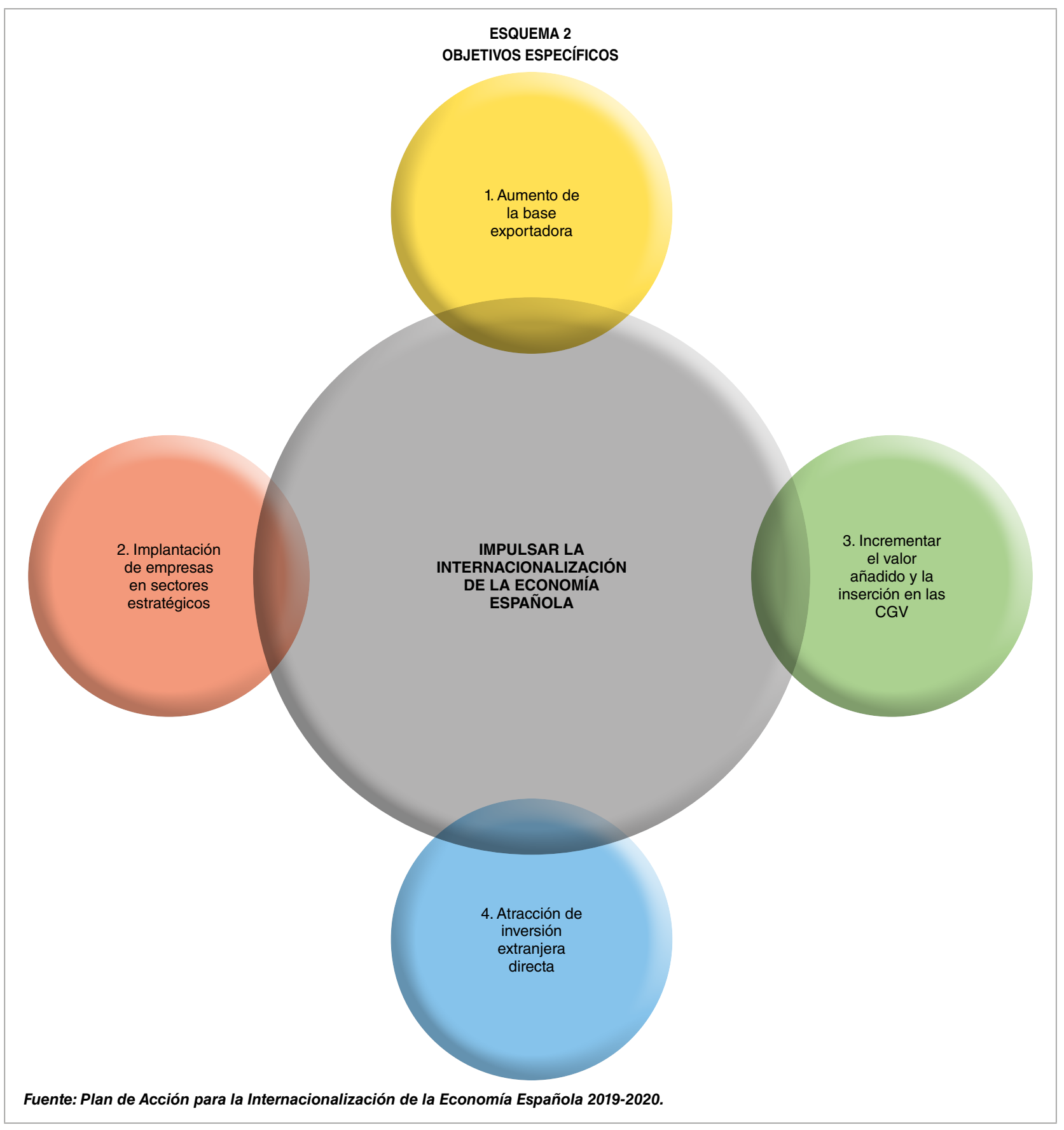

Por ello, solo se asocian indicadores de actividad a aquellos objetivos intermedios relacionados con las políticas de internacionalización que llevan a cabo los distintos instrumentos comerciales y financieros de apoyo a la internacionalización. Estos indicadores podrán ser complementados con otros de actividad, de satisfacción de los clientes, etcétera, que incorporen los distintos instrumentos en sus respectivos planes.

A la luz de la evolución de los distintos indicadores, se realizará un seguimiento y valoración de este plan, con el objetivo último de impulsar las mejoras que puedan resultar necesarias, si bien muchos de los factores y variables que tienen impacto en el ámbito $\triangleright$ 
de la internacionalización de la economía escapan del ámbito de actuación del plan y del propio Gobierno, siendo necesario tener en cuenta este extremo a la hora de realizar una evaluación rigurosa y adecuada del efecto que el plan tenga sobre la internacionalización de la economía española.

\section{Principales medidas del Plan de Acción 2019-2020}

Las medidas concretas a desarrollar en el bienio 2019-2020 buscan incidir en los objetivos señalados y se agrupan en torno a los seis ejes de actuación que señala la estrategia. Se identifican asimismo los instrumentos más adecuados para su ejecución.

En este plan de acción cabe destacar la actividad del ICEX, que prestará especial atención a las pymes, para contribuir a su competitividad y a la creación de empleo. Así, en este plan bienal, el ICEX trabajará para:

1. Afianzar la cultura orientada al cliente desde una entidad que presta servicios de promoción e información integrales, personalizados y de alto valor añadido, realizando una evaluación continua de las medidas, programas e instrumentos $y$ analizando su impacto, así como el grado de satisfacción de los usuarios.

2. Integrar la sostenibilidad y la digitalización de forma transversal en la entidad, tanto internamente como en sus políticas y programas. La inclusión de la sostenibilidad obedece a la creencia de que la sostenibilidad es también un elemento de competitividad de nuestras empresas: además del valor reputacional de la marca, puede tener incidencia directamente en la reducción de costes en el proceso productivo o en el acceso a nuevos mercados y fuentes de recursos productivos.

3. Vertebrar y reforzar el ecosistema de internacionalización a través de alianzas estratégicas que permitan aumentar la especialización, promover la innovación y aumentar la oferta de servicios a las empresas en el ámbito de la internacionalización.

Por su parte, los instrumentos y organismos que ofrecen apoyo financiero oficial a la internacionalización (Fondo para la Internacionalización de la Empresa -FIEM-, Compañía Española de Seguros de Crédito a la Exportación -CESCE-, Compañía Española de Financiación del Desarrollo —COFIDES - y el Instituto de Crédito Oficial - ICO-), mediante la financiación o cobertura de riesgos, incentivan que los agentes privados, tanto exportadores como financiadores, entren en operaciones de internacionalización. Los instrumentos de apoyo oficial complementan y completan el mercado, apalancando fondos públicos para la promoción de la internacionalización.

El ámbito de aplicación de estos instrumentos está siempre vinculado a la existencia de fallos de mercado. Su papel es especialmente relevante en momentos de crisis, cuando el mercado de fondos prestables es objeto de distorsiones y el crédito a las empresas se ve restringido de forma generalizada. Así, en ese contexto, es necesario reforzar la capacidad de los instrumentos de apoyo financiero a la internacionalización para evitar que nuestras empresas se encuentren en desventaja frente a otros competidores en un contexto de restricciones del crédito.

Ahora bien, en la situación actual de abundante liquidez en los mercados, subsisten $\triangleright$ 
fallos de mercado que determinan el papel a desempeñar por estos instrumentos, que deben orientarse a cubrir los nichos no cubiertos por el mercado. Resulta también necesario redefinir su competitividad.

Al existir agentes $u$ operaciones que por su propia naturaleza se ven afectados por restricciones de crédito, independientemente del momento del ciclo económico, los instrumentos de apoyo financiero a la internacionalización siguen desempeñando un importante papel en momentos de crecimiento o estabilidad. Esto es especialmente evidente en el apoyo a las pymes, empresas de nueva creación, innovadoras o para aquellas que se internacionalizan en países u operaciones relativamente más complejas o arriesgadas. Así, los instrumentos deben seguir en constante innovación y mejora, mejorando también la coordinación entre los mismos, para que las empresas puedan aprovechar todo el potencial que ofrece el sistema de instrumentos de apoyo financiero a la internacionalización.

Por otro lado, el apoyo financiero oficial a la internacionalización se desarrolla en un entorno sujeto a constante evolución, en el que las reglas internacionales están siendo objeto de revisión, y en competencia con una amplia variedad de instrumentos de apoyo público de otros países que ofrecen condiciones cada vez mejores. Ello obliga a dotar a nuestros instrumentos de apoyo financiero oficial de mayor competitividad, redefiniendo aspectos como los riesgos a asumir, su flexibilidad y rapidez en su gestión, y potenciando la coordinación entre ellos.

Como se ha señalado, las actuaciones de ICEX y las de los organismos e instrumentos financieros de apoyo a la internacionalización se organizarán, junto a las actuaciones de otros agentes relevantes, en torno a seis ejes.
Eje 1. Ofrecer un apoyo a la internacionalización cada vez más adaptado a las necesidades y al perfil de nuestras empresas. Particularmente con el foco en mejorar el acceso de las pymes a los mercados exteriores

El tejido empresarial español está muy atomizado, con una altísima concentración en microempresas, el 95,7\%. La pequeña dimensión de la pyme se traduce en menor productividad, falta de fuerza para negociar con proveedores, escasez de recursos que puede dedicar a internacionalización e innovación, y dificultad para acceder a financiación externa. Es necesario, por tanto, impulsar medidas de apoyo específico a las pymes y reformas encaminadas a mejorar su tamaño, lo que revertirá en su crecimiento y, por consiguiente, en su internacionalización.

Así, en el marco de este plan se diseñarán y potenciarán nuevos programas de apoyo a la internacionalización adaptados a las necesidades de las empresas, teniendo en cuenta especialmente las particularidades de las pymes, y se promoverá espacios de encuentro en los que conectar a nuestros operadores con los mercados y con redes y comunidades empresariales.

Se revisarán y adaptarán los instrumentos oficiales de apoyo financiero, con la finalidad de incrementar su agilidad, su flexibilidad y el ámbito de aplicación, para que se consiga un mayor y mejor uso de los mismos por parte de nuestras empresas.

Se mejorará el acceso a la información sobre los distintos programas e instrumentos, particularmente de las pymes, que tienen mayores dificultades para ello.

Asimismo, teniendo en cuenta las menores oportunidades de las mujeres para el emprendimiento y el desarrollo de empresas y, en concreto, el acceso a la internacionalización, el $\triangleright$ 
plan contempla la aplicación de medidas para fomentar e incentivar la participación de mujeres en los programas gubernamentales de apoyo a la internacionalización y estudiar los factores que pueden obstaculizar el emprendimiento internacional femenino como factor de competitividad para, en su caso, poner en marcha programas específicos.

Otro aspecto fundamental de este plan es subrayar el vínculo de la internacionalización con la sostenibilidad y la responsabilidad de las empresas, de manera que estas integren en su estrategia el impacto que generan en su entorno y mejoren así su capacidad de competir y de aprovechar las oportunidades de los mercados globales.

\section{Eje 2. Incorporar la innovación,} la tecnología, la marca y la digitalización a la internacionalización

Se incluyen medidas para incorporar la innovación tecnológica a la internacionalización, favorecer la creación y consolidación de las marcas de las empresas y mejorar la imagen país como marca colectiva, así como para ayudar a las empresas a incorporar la digitalización en sus modelos de negocio. Si bien muchas de las políticas públicas de apoyo a estas materias escapan del ámbito de actuación de la Secretaría de Estado de Comercio, esta colaborará estrechamente con los distintos departamentos ministeriales y entidades con el objetivo de lograr la mayor incidencia posible en la internacionalización.

\section{Eje 3. Desarrollar el capital humano para la internacionalización}

Se incorporan medidas para aumentar la formación de calidad en internacionalización que precisan nuestras empresas y particularmente los jóvenes, utilizando las nuevas tecnologías y promoviendo y difundiendo los programas superiores y becas especializadas. Asimismo, se consolidarán y difundirán los programas de estudiantes en prácticas y se internacionalizará el sistema universitario español.

También se fomentarán los programas de movilidad laboral internacional, especialmente los dirigidos a los jóvenes, con el fin de que nuestro país disponga de unos recursos humanos mejor preparados para acompañar a las empresas españolas en sus procesos de internacionalización y para atraer el talento extranjero, facilitando la entrada y residencia en nuestro país de profesionales altamente cualificados, emprendedores, traslados intraempresariales, investigadores e inversores extranjeros.

\section{Eje 4. Aprovechar mejor las oportunidades de negocio derivadas de la política comercial común y de las instituciones financieras $y$ organismos multilaterales}

La Secretaría de Estado de Comercio promoverá una política comercial progresista, apostando por un sistema multilateral abierto, basado en normas y que rechaza cualquier forma de proteccionismo.

Con vistas a aprovechar mejor las oportunidades de negocio derivadas de la política comercial común y de las instituciones financieras y organismos multilaterales, se trabajará para que las empresas puedan contar con mercados cada vez más abiertos en los que se respeten las reglas de las que nos hemos dotado. En este sentido, la Secretaría de Estado de Comercio realizará conferencias, jornadas técnicas y utilizará otros medios de difusión para que las empresas españolas puedan $\triangleright$ 
aprovechar en mayor medida las ventajas que ofrecen los acuerdos de libre comercio que firma la UE con terceros mercados.

Asimismo, se instará a que las negociaciones comerciales de nuevos acuerdos de libre comercio en el seno de la UE tengan en cuenta capítulos ambiciosos en materia de desarrollo sostenible, comercio de bienes y servicios, igualdad de género y pymes, de acuerdo con los ODS de la Agenda 2030 y el Acuerdo de París de lucha contra el cambio climático. Asimismo, el plan incorpora medidas para dar a conocer a nuestras empresas los beneficios de estos acuerdos y los mecanismos para aprovecharlos.

Por otro lado, se instará, igualmente, a que la Comisión Europea realice un adecuado seguimiento de la correcta aplicación de los acuerdos comerciales y de inversión ya suscritos.

El plan afronta asimismo la detección y eliminación de barreras arancelarias y no arancelarias e incorpora medidas para aumentar la capacidad de influencia de España en otros foros internacionales como la OCDE, la UNCTAD, las diferentes instituciones financieras internacionales (IFI), Naciones Unidas y otros organismos internacionales.

El plan incluye también medidas para fomentar la participación de las empresas españolas en proyectos financiados por las IFI y en los proyectos promovidos a través de los instrumentos de ayuda externa de la UE, así como para ayudar a nuestras empresas a superar las barreras encontradas en licitaciones y compras públicas de organismos multilaterales.

\section{Eje 5. Potenciar la captación y consolidación de la inversión extranjera de alto valor añadido}

El plan incorpora medidas de atracción de inversiones estratégicas en países y sectores prioritarios; el impulso de un plan de promoción de España como plataforma global de negocios e inversiones; el refuerzo del Plan de Sedes, centrado en América Latina y la potenciación de programas de apoyo a las inversiones tecnológicas y al emprendimiento en sectores y actividades innovadores.

\section{Eje 6. Reforzar la coordinación y complementariedad de las acciones de todos los actores relevantes en materia de internacionalización}

El plan establece mecanismos para coordinar las actuaciones en materia de internacionalización que se lleven a cabo por las diferentes Administraciones e instituciones del sector público que actúan en apoyo a la internacionalización. También se buscarán sinergias con otras políticas de otros ámbitos de la Administración como la transición ecológica y lucha contra el cambio climático, políticas migratorias, terrorismo y lucha contra el blanqueo de capitales y corrupción, entre otros.

Se establecerá un diálogo fluido con el sector privado, de forma que se asegure que el plan responde a sus orientaciones, respetando así el principio de complementariedad de la actuación pública.

\section{PASE (Países con Actuación Sectorial y Estratégica)}

Por su carácter novedoso y especial relevancia para el desarrollo de la estrategia y del plan, se exponen brevemente, en este apartado, los criterios para la selección de Países con Actuación Sectorial Estratégica.

El ejercicio PASE responde a la necesidad de identificar, desde el punto de vista $\square$ 
geográfico y sectorial, los sectores de oportunidad en determinados mercados que mejor encajan con nuestra oferta exportable y donde las empresas españolas cuentan con un amplio margen de mejora para consolidar su presencia en el exterior. Este nuevo enfoque supone una reestructuración de los Planes Integrales de Desarrollo de Mercados (PIDM), lanzados por la Secretaría de Estado de Comercio en 2005 con el objetivo de diversificar los mercados de destino de nuestra exportación e inversión. El ejercicio PASE introduce el componente sectorial, junto al geográfico, a la hora de diseñar las medidas a realizar, buscando adecuar el desempeño de nuestro sector exterior a nuestro potencial.

La elección de los PASE se ha realizado tomando como base un análisis cuantitativo de una serie de indicadores objetivos sobre el potencial de los mercados para nuestras empresas, complementado con un análisis cualitativo. Los PASE se han seleccionado partiendo de aquellos países que, no perteneciendo a la UE o la EFTA, son uno de los principales destinos mundiales de la exportación de bienes y servicios o uno de los principales destinos de la exportación española. El potencial de estos países para la internacionalización de las empresas españolas se valoró teniendo en cuenta variables y criterios como la dimensión y evolución de su mercado, su grado de apertura y la facilidad de acceso a los mercados, las exportaciones e inversiones españolas, su estabilidad macrofinanciera o el interés manifestado por los empresarios españoles. Estos criterios cuantitativos se complementaron con la información proporcionada por los distintos instrumentos que componen la Secretaría de Estado de Comercio, en especial ICEX y la red de Oficinas Económicas y Comerciales de España en el Exterior.

Los países seleccionados en esta primera fase son los siguientes: Brasil, Canadá, China,
Corea del Sur, Estados Unidos, India, Japón, Marruecos, México, Rusia, Sudáfrica y Turquía. Para cada uno de ellos se ha identificado una serie de sectores estratégicos, así como unas actuaciones concretas a desarrollar en el bienio 2019-20. En ningún caso se trata de una lista excluyente, es decir, no se va a dejar de realizar actuaciones determinadas en apoyo de la internacionalización en otros sectores y países no incluidos.

Con carácter bienal se procederá, además, al seguimiento, evaluación y, en su caso, revisión de los países y sectores seleccionados, teniendo en cuenta que se trata de una iniciativa de medio-largo plazo y, por tanto, dinámica, y dependiente de una realidad en constante cambio.

\section{Conclusión}

El Plan de Acción para la Internacionalización de la Economía Española 2019-2020 refleja el grado de ambición del Gobierno y su compromiso con el impulso de la internacionalización de nuestra economía.

La aprobación de la Estrategia de Internacionalización 2017-2027 supuso un importante avance al introducir un marco estratégico a medio-largo plazo para el fomento de la internacionalización, que se desarrolla a través de planes de acción bienales, que permiten la adaptación a las circunstancias cambiantes sin perder de vista el compromiso a largo plazo. Este plan aspira a consolidar la internacionalización como pilar del crecimiento sostenible y del empleo, en el que la coordinación de todos los actores relevantes y la orientación del sector privado son fundamentales.

Así, el Plan de Acción 2019-2020 persigue consolidar la tendencia de aumento de la $\triangleright$ 
base exportadora - que ha permitido que las empresas que exportan regularmente superen ya las 50.000 - que nuestra economía sea más competitiva y diversificada, y que España se consolide como un inversor mundial de referencia, así como un destino atractivo para la inversión extranjera. Para ello, resulta esencial apostar firmemente por una progresiva liberalización del comercio en el marco de un sistema comercial multilateral abierto y basado en normas, así como ofrecer un apoyo a la internacionalización cada vez más adaptado a las necesidades específicas de cada tipo de empresa, en particular, de las pymes.

El Plan de Acción 2019-2020 será presentado tanto en el seno del Congreso como en el del Senado, con el objetivo de avanzar para que la política de internacionalización sea una auténtica política de Estado, como viene reclamando el sector privado. Asimismo, será objeto de una evaluación cuyos resultados serán públicos, con la que se busca asegurar la calidad y eficacia de las actuaciones recogidas.

\section{Bibliografía}

[1] Ministerio de Economía, Industria y Competitividad (2017). La Estrategia de Internacionalización de la Economía Española 20172027. Recuperado de http://www.mineco.gob. es/stfls/mineco/comercio/pdf/170913_ Estrategia_Internacionalizacion_2017.pdf

[2] Ministerio de Industria Comercio y Turismo (2019). El Plan de Acción para la Internacionalización de la Economía Española 2019-2020. Recuperado de http://www.comercio.gob.es/ es-ES/PDF/portada/Plan\%20Internacionalizaci\%C3\%B3n\%2019-20.pdf

[3] Ministerio de Industria Comercio y Turismo (2019). La Estrategia PASE (Países con Actuación Sectorial Estratégica). Recuperado de http://www.comercio.gob.es/es-ES/comercio-exterior/instrumentos-apoyo/Paginas/ Pa\%C3\%ADses-con-Actuaci\%C3\%B3nSectorial-Estrat\%C3\%A9gica.aspx

[4] Subdirección General de Análisis y Estrategia de Internacionalización (2017). La estrategia de internacionalización de la economía española 2017-2027. Boletín Económico de ICE, 3093. Recuperado de http://www.revistasice.com/ index.php/B/CE/article/view/5674 